\title{
Development of a Hypoallergenic Recombinant Parvalbumin for First-in-Man Subcutaneous Immunotherapy of Fish Allergy
}

Laurian Zuidmeer-Jongejan $^{a}$ Hans Huber ${ }^{b}$ Ines Swobodac Neil Rigby ${ }^{d}$

Serge A. Versteeg ${ }^{a}$ Bettina M. Jensen ${ }^{e}$ Suzanne Quaak $^{f} \quad$ Jaap H. Akkerdaas $^{a}$

Lars Blom $^{\mathrm{e}}$ Juan Asturias ${ }^{\mathrm{g}}$ Carsten Bindslev-Jensen ${ }^{\mathrm{h}}$ Maria L. Bernardi ${ }^{\mathrm{i}, \mathrm{k}}$

Michael Clausen $^{j}$ Rosa Ferrara ${ }^{i, k}$ Martina Hauer ${ }^{b}$ Jet Heyse ${ }^{f} \quad$ Stephan Kopp $^{b}$

Marek L. Kowalski' Anna Lewandowska-Polak' Birgit Linhart ${ }^{c}$ Bernhard Maderegger ${ }^{b}$

Bernard Maillere $^{m}$ Adriano Mari ${ }^{i, k}$ Alberto Martinez ${ }^{g} \quad$ E.N. Clare Mills ${ }^{d, n}$

Angela Neubauer ${ }^{b}$ Claudio Nicoletti ${ }^{d}$ Nikolaos G. Papadopoulos ${ }^{\circ}$

Antonio Portoles $^{p}$ Ville Ranta-Panula ${ }^{r}$ Sara Santos-Magadan $^{q}$ Heidi J. Schnoor ${ }^{\mathrm{e}}$

Sigurveig T. Sigurdardottir ${ }^{i}$ Per Stahl-Skov $^{s}$ George Stavroulakis ${ }^{\circ}$ Georg Stegfellner $^{\mathrm{b}}$

Sonia Vázquez-Cortés ${ }^{q}$ Marianne Witten ${ }^{\mathrm{e}}$ Frank Stolz $^{\mathrm{b}}$ Lars K. Poulsen $^{\mathrm{e}}$

Montserrat Fernandez-Rivas ${ }^{q}$ Rudolf Valenta ${ }^{c}$ Ronald van Ree ${ }^{a, t}$

\begin{abstract}
a Department of Experimental Immunology, Academic Medical Center, Amsterdam, The Netherlands; ${ }^{\mathrm{b}}$ Biomay AG and ${ }^{\mathrm{c}} \mathrm{Medical}$

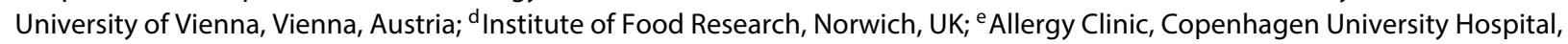

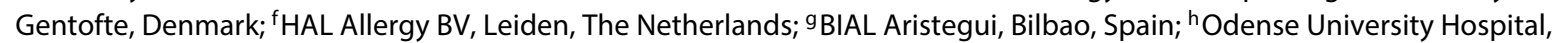

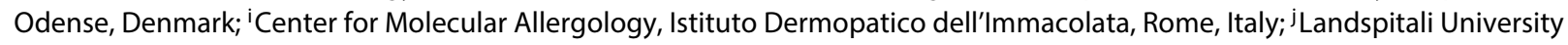
Hospital Reykjavik, Reykjavik, Iceland; ' Associated Centers for Molecular Allergology, CAAM, Rome, Italy; 'Department of Immunology, Rheumatology and Allergy, Medical University of Lódz, Lódz, Poland; m CEA, Institute of Biology Technologies, Paris, France; ${ }^{n}$ Institute of Inflammation and Repair, Manchester Academic Health Science Centre, Manchester Institute of Biotechnology, University of Manchester, Manchester, UK; ${ }^{\circ}$ Department of Allergy, Second Pediatric Clinic, National Kapodistrian

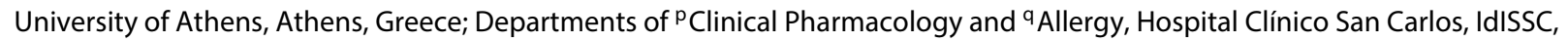

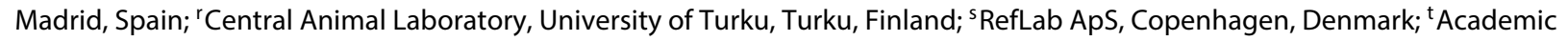
Medical Center, Department of Otorhinolaryngology, Amsterdam, The Netherlands
\end{abstract}

\section{Key Words}

Allergen mutants · Carp · Cyprinus carpio · FAST · Fish .

Food allergy $\cdot$ Immunotherapy $\cdot$ Parvalbumin $\cdot$ Recombinant hypoallergenic allergens · Toxicity

This project was funded by the EU through the FAST project (201871).

\section{Abstract}

Background: The FAST (food allergy-specific immunotherapy) project aims at developing safe and effective subcutaneous immunotherapy for fish allergy, using recombinant hypoallergenic carp parvalbumin, Cyp c 1. Objectives: Preclinical characterization and good manufacturing practice (GMP) production of mutant Cyp (mCyp) c 1. Methods: Esch-

\section{KARGER 125}

C) 2015 S. Karger AG, Basel

$1018-2438 / 15 / 1661-0041 \$ 39.50 / 0$

E-Mail karger@karger.com

www.karger.com/iaa
Correspondence to: Dr. Laurian Zuidmeer-Jongejan

Department of Experimental Immunology

Academic Medical Center

Meibergdreef 9, NL-1105 AZ Amsterdam (The Netherlands)

E-Mail l.zuidmeer@amc.uva.nl 
erichia coli-produced mCyp c 1 was purified using standard chromatographic techniques. Physicochemical properties were investigated by gel electrophoresis, size exclusion chromatography, circular dichroism spectroscopy, reversephase high-performance liquid chromatography and mass spectrometry. Allergenicity was assessed by ImmunoCAP inhibition and basophil histamine release assay, immunogenicity by immunization of laboratory animals and stimulation of patients' peripheral blood mononuclear cells (PBMCs). Reference molecules were purified wild-type Cyp c 1 (natural and/or recombinant). GMP-compliant alum-adsorbed mCyp c 1 was tested for acute toxicity in mice and rabbits and for repeated-dose toxicity in mice. Accelerated and real-time protocols were used to evaluate stability of $\mathrm{mCyp} \mathrm{c} 1$ as drug substance and drug product. Results: Purified mCyp c 1 behaves as a folded and stable molecule. Using sera of 26 double-blind placebo-controlled food-challenge-proven fish-allergic patients, reduction in allergenic activity ranged from 10- to 5,000-fold (1,000-fold on average), but with retained immunogenicity (immunization in mice/rabbits) and potency to stimulate human PBMCs. Toxicity studies revealed no toxic effects and real-time stability studies on the $\mathrm{Al}(\mathrm{OH})_{3}$ adsorbed drug product demonstrated at least 20 months of stability. Conclusion: The GMP drug product developed for treatment of fish allergy has the characteristics targeted for in FAST: i.e. hypoallergenicity with retained immunogenicity. These results have warranted first-in-man immunotherapy studies to evaluate the safety of this innovative vaccine.

(c) 2015 S. Karger AG, Basel

\section{Introduction}

Fish frequently cause IgE-mediated food allergy [1]. Like some other foods (peanuts and tree nuts, and in the early years of life milk and egg), fish allergy often presents with severe, sometimes life-threatening symptoms $[1,2]$. Currently, the only treatment for food allergy is avoidance and rescue medication. The need for effective and safe immunotherapy for food allergy is clear, and initiatives to develop in particular oral or sublingual treatments are currently underway [3, and references therein]. Over 15 years ago, subcutaneous immunotherapy (SCIT) was evaluated for the treatment of peanut allergy using aqueous peanut extract $[4,5]$, i.e. without adsorption to aluminum hydroxide (alum), for example, as is commonly done for SCIT in Europe. Although these studies demonstrated a promising level of efficacy, severe unacceptable side effects were frequently observed. Since then, further attempts to develop SCIT for food allergy were considered too dangerous. With the advent of recombinant technology, new avenues have opened up [6], as it offers the opportunity to modify allergenic molecules into safer hypoallergenic derivatives using site-directed mutagenesis. On top of that, adsorption to alum may add a second layer of safety and effectiveness.

In 2008, the EU-funded FAST (food allergy-specific immunotherapy) project was started: one part aiming at the development of a subcutaneous treatment for fish allergy based on an alum-adsorbed hypoallergenic mutant of the major fish allergen parvalbumin $[7,8]$. Parvalbumin has been reported to play a very dominant role, with the majority of fish-allergic patients being sensitized mainly to this allergen in a broad spectrum of fish species $[2,9,10]$. The first parvalbumin identified and characterized as an allergen was the major codfish allergen, Gad c $1[11,12]$. Parvalbumins are calcium-binding muscle proteins of $10-13 \mathrm{kDa}$, which are very resistant to heat, denaturation and proteolysis $[10,11]$ and are ubiquitous in most common dietary fish $[2,7,8]$. They are characterized by three (of which two are active) helix-loop-helix $\mathrm{Ca}^{2+}$-binding domains [13-15], and $\mathrm{Ca}^{2+}$ depletion was shown to reduce IgE binding to parvalbumin [16]. Carp parvalbumin (Cyp c 1) covers most cross-reactive IgE epitopes present in the family of homologous fish parvalbumins [16]. Swoboda et al. [17] produced a recombinant version of Сyp c 1, and, in agreement with the impact of $\mathrm{Ca}^{2+}$ depletion, they provided evidence that mutations in the two active $\mathrm{Ca}^{2+}$ binding sites also resulted in significantly reduced IgE binding [8]. Based on these promising pilot data, the FAST project selected this mutant Cyp (mCyp) c 1 as a starting point for the development of an alum-adsorbed hypoallergenic parvalbumin vaccine for SCIT of fish allergy. In the present study, we describe the preclinical development of mCyp c 1 into a good manufacturing practice (GMP)-produced drug substance and alum-adsorbed drug product suitable to go into a first-inman phase I/IIa clinical immunotherapy trial.

\section{Materials and Methods}

Patients' Sera and Peripheral Blood Mononuclear Cells

Sera $(n=26)$ and peripheral blood mononuclear cells (PBMCs; $\mathrm{n}=30$ ) from adult patients with fish allergy proven by doubleblind placebo-controlled food challenge (DBPCFC; $n=24$ ) or cod allergy proven by open food challenge $(n=3)$ or a convincing history of cod-induced anaphylaxis $(n=3)$ from the 6 clinical centers participating in FAST (Madrid, Rome, Lódz, Athens, Reykjavik and Odense) were used to evaluate hypoallergenicity
Zuidmeer-Jongejan et al. 
and T-cell reactivity of mCyp $\mathrm{c} 1$. In addition, patients further had to have a positive skin prick test for fish ( $\geq 5 \mathrm{~mm}$, BIAL-Aristegui, Bilabao, Spain) and serum IgE against recombinant Cyp (rCyp) c 1 and recombinant Gad c $1\left(\geq 0.70 \mathrm{kU}_{\mathrm{A}} / \mathrm{l}\right)$. The study protocol was approved by the local ethics committee of each clinical center and all patients gave written informed consent to be enrolled in the study.

\section{Allergens}

Natural parvalbumin nCyp c 1 was purified from carp muscle, as described before [18]. Recombinant wild-type (WT) parvalbumin Cyp c 1.01 (EMBL accession No. AJ292211, rCyp c 1) and the mutagenesis, construction, Escherichia coli expression and final purification of the hypoallergenic mCyp c 1.01 (mCyp c 1) were performed as described by Swoboda et al. [8], only using the pET$28 \mathrm{~b}+$ vector (Novagen, New Orleans, La., USA) instead. Details of the production and characterization of non-GMP rCyp c 1 and GMP mCyp c 1 are described in the online supplementary material (for all online suppl. material, see www.karger.com/ doi/10.1159/000371657).

\section{Physicochemical Characterization}

The drug substance mCyp c 1 was physicochemically characterized in depth to assess identity, purity, integrity, homogeneity, molecular mass and aggregation state, using 1D and 2D gel electrophoresis, size exclusion chromatography (SEC), circular dichroism spectroscopy, reverse-phase (RP) high-performance liquid chromatography (HPLC) and mass spectrometry (MS). These methods are described in the online supplementary material. For quantification of rCyp c 1 and mCyp c 1, absorbance at $280 \mathrm{~nm}$ and the bicinchoninic acid protein assay kit (Sigma, Gillingham, UK) were used.

\section{Accelerated Stability Studies of $m C y p c 1$}

Samples were stored in aliquots at five different temperatures: $-80,-30,4,25$ and $40^{\circ} \mathrm{C}$. The temperature of the stored samples was monitored on a weekly basis. Samples were analyzed at baseline $(\mathrm{t}=0)$, and 3 and 6 months, using SDS-PAGE in conjunction with Coomassie staining, SEC and RP-HPLC, using the sample stored at $-80^{\circ} \mathrm{C}$ as reference. After thawing the 3-month samples, a small aliquot $(10 \mu \mathrm{l})$ was refrozen at $-80^{\circ} \mathrm{C}$ for subsequent MS at the 6-month time point, together with the 6-month samples. Details can be found in the online supplementary material.

\section{Assessment of Hypoallergenicity: ImmunoCAP Inhibition and}

Basophil Histamine Release Test

ImmunoCAP analysis was performed according to the manufacturer's instructions (Thermo Fisher Scientific, Uppsala, Sweden) using rCyp c 1 ImmunoCAPs (f355). For titrated IgE inhibition studies (inhibitor added in 10-fold dilutions from up to $100 \mu \mathrm{g}$ to less than $1 \mathrm{ng}$ ), $75 \mu \mathrm{l}$ serum was mixed with $75 \mu$ inhibitor (nCyp c 1 , rCyp c 1 or mCyp c 1) and incubated at room temperature for $1 \mathrm{~h}$ prior to ImmunoCAP analysis. PBS was used for the uninhibited control. Results were expressed as percent inhibition compared to the uninhibited control. In addition, concentrations needed for $50 \%$ inhibition were calculated for each serum-inhibitor combination.

Histamine release from basophil leukocytes was performed as previously described [19]. Details are described in the online supplementary material.

Development Hypoallergenic

Parvalbumin for SCIT
Immunogenicity Assessment: Laboratory Animals and Human PBMCs

Female New Zealand White rabbits were immunized on day 0 with $50 \mu \mathrm{g}$ rCyp c 1 or mCyp c 1 three times using TiterMax (TiterMax USA Inc., Norcross, Ga., USA) as adjuvant. A booster was given on day $35(25 \mu \mathrm{g}$ of antigen in $100 \mu \mathrm{l}$ of PBS three times). Plasma was collected before immunization and on days 60 and 74. Further details can be found in the online supplementary material.

Female BALB/c mice ( 6 weeks of age; $n=6$ ) were immunized subcutaneously with three different concentrations $(5,10$ and $20 \mu \mathrm{g}$ ) of aluminum hydroxide-adsorbed mCyp c 1 or rCyp c 1 , and boosted twice on days 18 and 36 . Serum was collected before immunization, on days 18 and 36 (boosting), and 2 weeks after the last boosting via puncture of the tail vein. Detection of allergenspecific mouse immunoglobulins by ELISA was done as described by Linhart et al. [20].

To assess T-cell reactivity to mCyp c 1, rCyp c 1 and nCyp c 1 , PBMCs from fish-allergic patients were purified locally at each clinical center using Lymphoprep (Medinor, Oslo, Norway) from $30 \mathrm{ml}$ heparinized blood and stained with carboxyfluorescein succinimidyl ester according to Parish et al. [21]. Details are described in the online supplementary material.

\section{Formulation of mCyp c 1 Drug Products and Real-Time}

Stability Testing

Formulation, adsorption, filling, labeling and packaging of the final product, as well as the real-time stability testing are described in detail in the online supplementary material.

\section{Toxicity Studies}

Acute Toxicity. For acute toxicity studies, the OECD fixeddose procedure (OECD Guideline 420) was conducted in two stages, a sighting study and a main study, on rodents (mice) and nonrodents (rabbits), to confirm the observations made in rodents. Details are described in the online supplementary material. In short, a dose of 10 or $0.3 \mathrm{mg} / \mathrm{kg}$ body weight (BW) of alumadsorbed mCyp c 1 (rodents and nonrodents, respectively) was given subcutaneously to a single animal. If there were no signs of toxicity after $24 \mathrm{~h}$, the dose was administered subcutaneously to a group of 4 rodent and 2 nonrodent animals, which were then observed for 14 days for possible clinical signs. After the observation period, gross necropsy was performed and macroscopic signs were recorded.

Repeated Dose. To provide information on possible toxic effects of alum-adsorbed mCyp c 1 during longer exposure, to identify possibly affected target organs and to provide an estimate of a no-observed-adverse-effect level of exposure, a 6-month repeated-dose study was performed, which followed the design of the planned clinical study in duration and injection of a weekly (maintenance) dose. Four groups (vehicle only, and 30, 100 and $300 \mu \mathrm{g} \mathrm{mCyp} \mathrm{c} 1 / \mathrm{kg} \mathrm{BW}$ ) of 30 male and 30 female mice, respectively, were injected subcutaneously with the test substance once a week, over a period of 6 months. Samples were collected at the end of the study for hematology, clinical chemistry and histopathological analysis as well as specific immunoglobulin determinations to mCyp c 1. Clinical signs, morbidity and mortality, BW and water and food consumption were monitored during the experimental period. Details are described in the online supplementary material. 


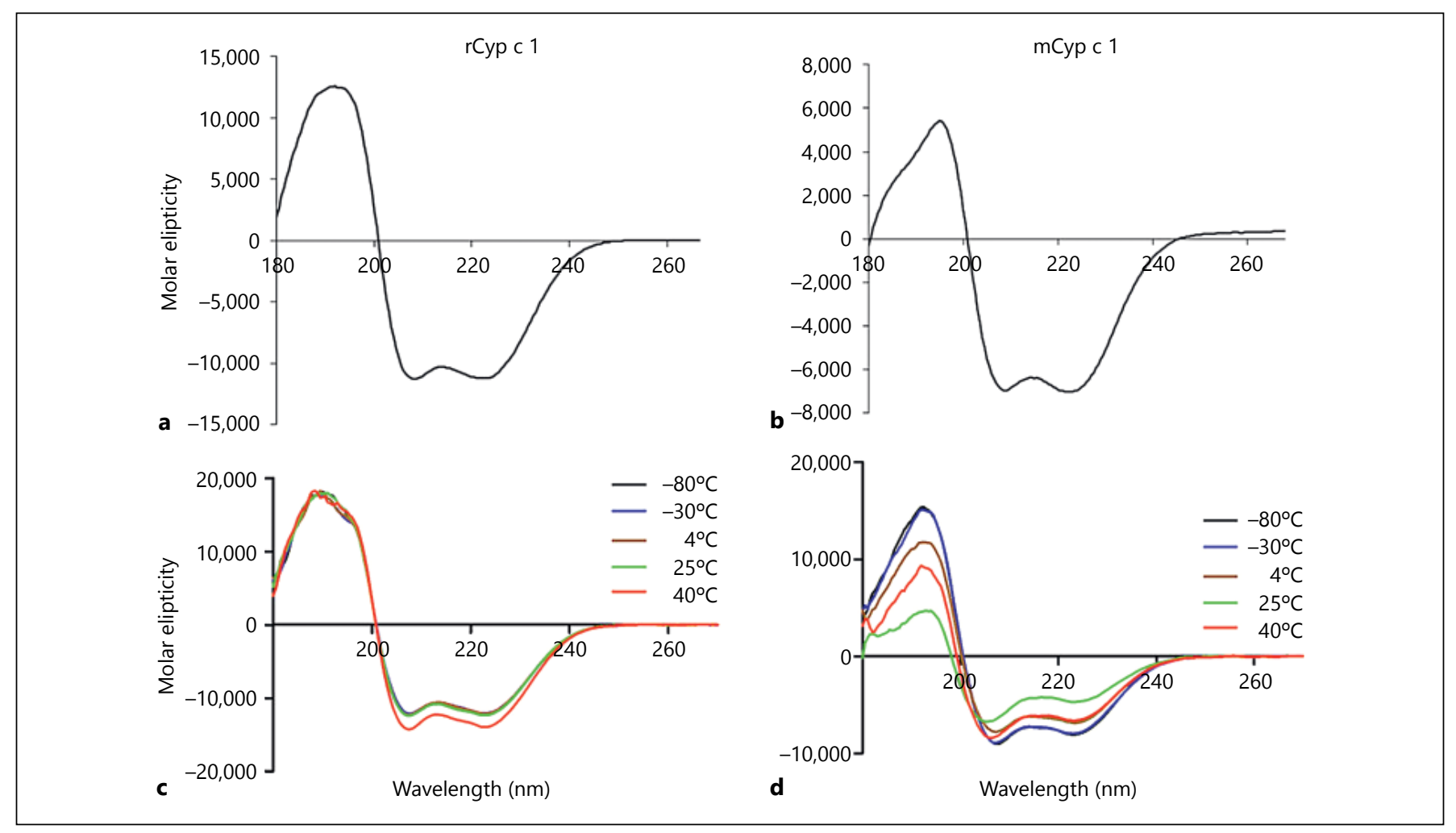

Fig. 1. Circular dichroism spectra of $\operatorname{rCyp~} \mathrm{c} 1(\mathbf{a}, \mathbf{c})$ and $\operatorname{mCyp} c 1(\mathbf{b}, \mathbf{d})$ molecules at $t=0(\mathbf{a}, \mathbf{b})$ and after stability studies ( $\mathrm{t}=6$ months; $\mathbf{c}, \mathbf{d})$.

\section{Results}

mCyp c 1 Is a Stable, Mixed Monomeric and Dimeric, Folded Protein

Physicochemical characterization of non-GMP mCyp c 1 and rCyp c 1 revealed that both are folded proteins dominated by $a$-helices (fig. 1a, b). On the other hand, on SDS-PAGE (fig. 2) and SEC, mCyp c 1 (fig. 3a, b) migrated at slightly lower apparent molecular mass, suggesting that the shape of the molecule most likely underwent some degree of change. Also, using RP-HPLC, mCyp c 1 and rCyp c 1 migrated at slightly different positions (fig. 4). MS analyses before (online suppl. fig. S1) and after $2 \mathrm{D}$ separation and trypsin digestion of nonGMP mCyp c 1 (online suppl. fig. S2 and table S1) revealed that the preparation next to the full-length molecule also contained a slightly shorter version of mCyp c 1 truncated C-terminally by 5 amino acids, and some minor contaminations with E. coli-derived molecules. In the final GMP batch, these E. coli-derived contaminations were significantly reduced (fig. 1; online suppl. fig. S3). Both mCyp c 1 and rCyp c 1 were also detected as dimers on SDS-PAGE (fig. 2), as was confirmed by the MS analysis after trypsin digestion (online suppl. S2 and table S1). The apparent propensity to dimerize was observed more dominantly for the mCyp $\mathrm{c} 1$ than for the rCyp c 1. In accelerated stability testing, both rCyp c 1 and mCyp $\mathrm{c} 1$ proved to be very stable after 6 months at up to $25^{\circ} \mathrm{C}$ (fig. 2 , as well as $1,3,4 \mathrm{~b}, \mathrm{c}$ ). In conclusion, the drug substance is stable and has a secondary structure very similar to the WT molecule, but the tendency to dimerize is higher.

\section{mCyp c 1 Shows Significantly Reduced Allergenic \\ Activity}

Titrated ImmunoCAP inhibition experiments were performed using sera from 26 DBPCFC-proven fish-allergic patients. Both nCyp c 1 and rCyp c 1 have very similar inhibitory potency (fig. 5a), on average reaching $50 \%$ inhibition at a concentration of $0.1-1.0 \mu \mathrm{g} / \mathrm{ml}$ (fig. 5b). For mCyp c 1, 50\% inhibition was not reached in most cases (24/26), reaching a plateau below $25 \%$ inhibition at $75 \mu \mathrm{g} / \mathrm{ml}$ on average. This level of inhibition was reached on average around $75 \mathrm{ng} / \mathrm{ml}$ for the WT mole-
44

Int Arch Allergy Immunol 2015;166:41-51 DOI: $10.1159 / 000371657$
Zuidmeer-Jongejan et al. 


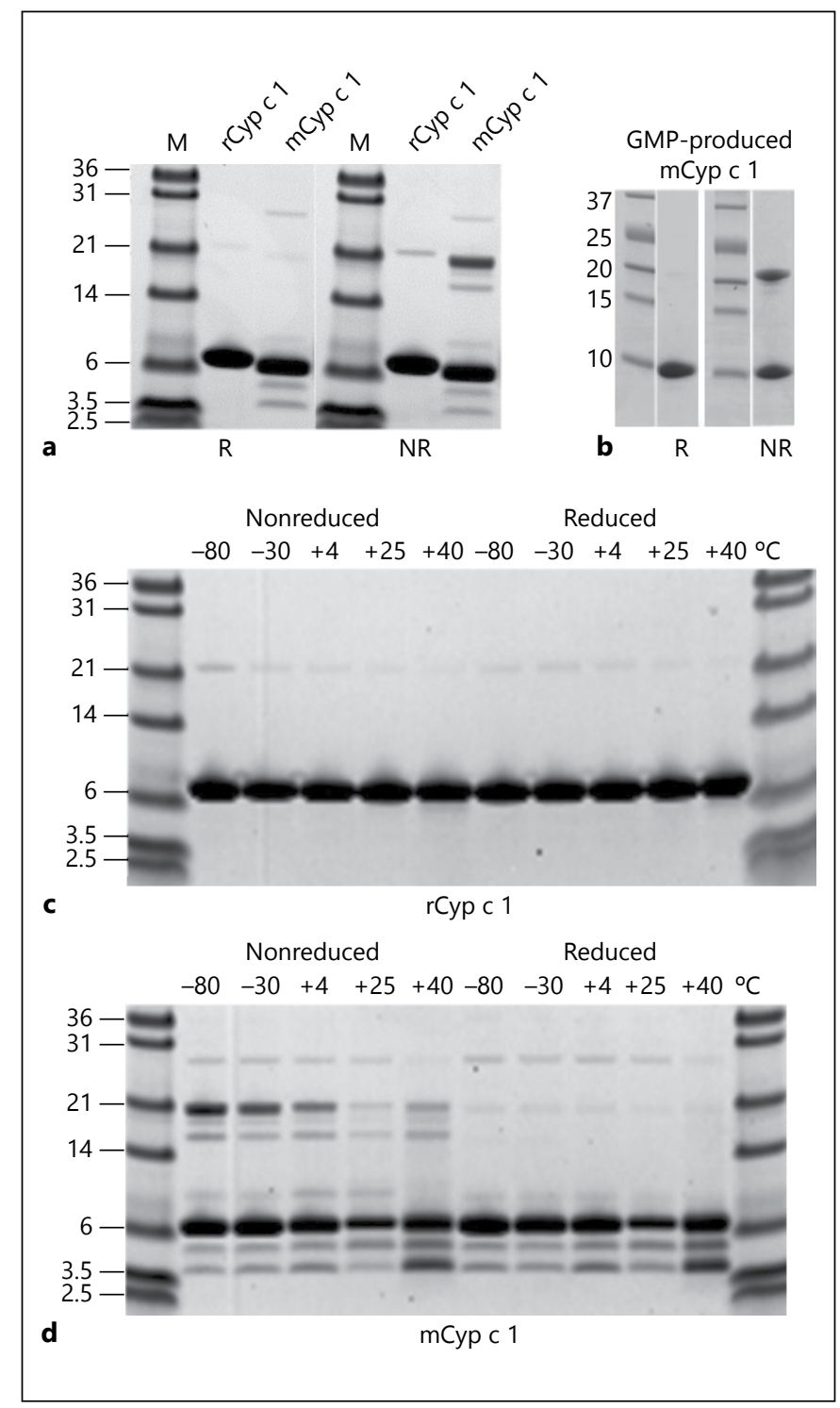

Fig. 2. SDS-PAGE analysis [reduced (R) and nonreduced(NR)] of the rCyp c 1 and mCyp c 1 (a), the GMP-produced mCyp c 1 (b) and both molecules after the stability study ( $t=6$ months; $\mathbf{c}, \mathbf{d})$.

cules, implying a 1,000-fold reduction in IgE reactivity. There were two clear exceptions where $50 \%$ inhibition was reached, but the reduction in IgE reactivity was still 10 - and 100-fold, respectively.

Basophil histamine release testing was performed for $24 / 26$ patients tested in ImmunoCAP inhibition. Sensitization of basophils with sera of $11 / 24$ patients with DBPCFC-proven fish allergy did not result in significant histamine release, even with the WT molecule. This can most likely be explained by insufficient sensitivity of the basophil histamine release test for low-level specific IgE [median $3.9 \mathrm{kU} / \mathrm{l}$, interquartile range (IQR) 1.4-5.4 $\mathrm{kU} / \mathrm{l}$, vs. a median of $13.2 \mathrm{kU} / \mathrm{l}$, IQR $9-23.8 \mathrm{kU} / \mathrm{l}$ for the sera that did facilitate release]. Histamine release with sera of the other 13 patients confirmed that mCyp c 1 has a 100 - to 1,000-fold reduction in allergenic activity (fig. 6).

\section{Immunization with $m$ Cyp $c 1$ Induces $r C y p c$}

1-Cross-Reactive IgG Antibodies in Mice and Rabbits

rCyp c 1 and mCyp c 1 were compared for immunogenicity in rabbits and mice, using IgG recognition of the WT molecule as primary outcome. In both rabbits and mice, mCyp c 1 induced an IgG response that was cross-reactive with rCyp c 1. In mice, rCyp c 1 induced a slightly weaker response than mCyp $c 1$. In rabbits, the limited number of animals did not warrant such comparison (fig. 7).

\section{mCyp c 1 Induces Specific T-Cell Responses}

PBMCs from 14 fish-allergic patients were isolated and stimulated with rCyp c 1, nCyp c 1 and mCyp c 1 . All three molecules induced weak but significant proliferation (online suppl. fig. S4).

\section{Alum-Adsorbed mCyp c 1 Lacks Toxic Effects}

A non-GMP batch of mCyp $\mathrm{c} 1$ was adsorbed to alum at $1.1 \mathrm{mg} / \mathrm{ml}$ protein (based on absorbance at A $280 \mathrm{~nm}$ ) to $2 \mathrm{mg} / \mathrm{ml}$ of alum. This batch was used for acute and repeated-dose toxicity testing. A single subcutaneous administration of 0.3 and $10 \mathrm{mg} / \mathrm{kg}$ antigen (in rabbits and mice, respectively) did not result in clinical signs of toxicity in any of the animals during the 14-day observation period. No signs of toxicity were observed at necropsy nor were test-item-related effects on BW or BW gain observed. Based on this study, the no-observed adverse effect level of mCyp c 1 is above $10 \mathrm{mg} / \mathrm{kg} \mathrm{BW}$ in mice and above $0.3 \mathrm{mg} / \mathrm{kg} \mathrm{BW}$ in rabbits. Based on average BWs of mice $(\sim 30 \mathrm{~g})$ and rabbits $(2.5-3 \mathrm{~kg})$, these quantities are $>10,000$ times and $>300$ times higher, respectively, than the highest dose foreseen in the protocol for the first-inman clinical trial, i.e. $60 \mu \mathrm{g}$ per injection, being close to $0.9 \mu \mathrm{g} / \mathrm{kg} \mathrm{BW}$ for an average BW of $70 \mathrm{~kg}$.

A 26-week four-armed repeated-dose toxicity study was performed in mice, using alum alone (placebo) and three dose levels of alum-adsorbed mCyp c 1 . The alum concentration in the three active arms was kept constant. With respect to food consumption, BW, clinical signs, clinical chemistry and hematological determinations and histopathological evaluations, no differences between mCyp c 1-treated mice and mice that had received placebo were observed. Pharmacodynamics were evaluated 


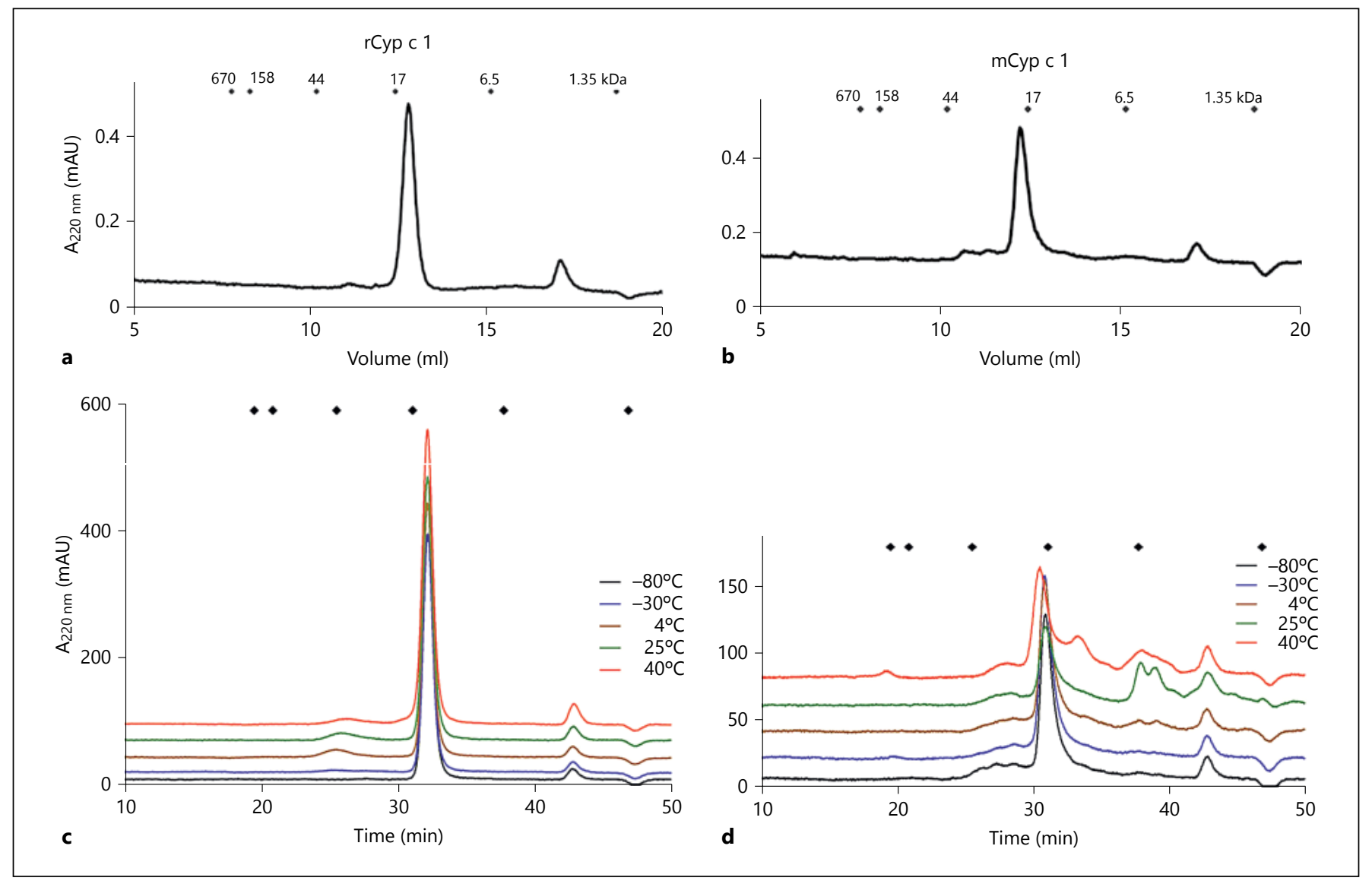

Fig. 3. SEC spectra of $\operatorname{rCyp} c 1(\mathbf{a}, \mathbf{c})$ and $\operatorname{mCyp} c 1(\mathbf{b}, \mathbf{d})$ at $t=0(\mathbf{a}, \mathbf{b})$ and after stability studies $(\mathrm{t}=6$ months; $\mathbf{c}, \mathbf{d})$.

by assessment of mCyp c 1-specific IgG1, IgG2a and IgE antibodies and total IgE responses (online suppl. fig. S5). There was a statistically significant $(\mathrm{p}<0.05)$ increase compared to the controls in all dose groups for specific IgG1, IgG2a and total IgE, and the low dose for specific IgE. There were differences between male and female animals that are detailed in the online supplementary material; however, we believe these differences are inherent to the known differences in immune response between sexes rather than the molecule used for injection.

\section{GMP Batch}

A GMP batch has been produced and tested using the same methods as the preclinical non-GMP batch used for toxicity testing. The yield (after purification) was $58.6 \mathrm{mg} / \mathrm{l}$. The GMP drug substance had characteristics similar to those reported for the non-GMP batch (online suppl. material). The GMP drug substance was subsequently adsorbed to aluminum hydroxide $(2 \mathrm{mg} / \mathrm{ml})$ at a concentration of 0.7 $\mathrm{mg} / \mathrm{ml}$. The product was filled and samples were taken to do a quality assessment, including a test for sterility, and to perform a real-time stability study. The methods and results are described in detail in the online supplementary material text and table S2. Based on these analyses and the outcome of the toxicity studies, ethical and regulatory approval has been obtained, making the product a suitable first-in-human safety phase I/IIa clinical trial in fish-allergic patients.

\section{Discussion}

In the present study, we describe the preclinical development of a drug product for first-in-man subcutaneous treatment of fish allergy. Why fish allergy? Although the prevalence is certainly lower than that of peanut or tree nut allergy, the risk of severe reactions is shared with these more common allergies. Financial support from the European Union 7th Framework Program has made it possible to develop a treatment for a rare but potentially severe disease. A more pragmatic
Zuidmeer-Jongejan et al. 


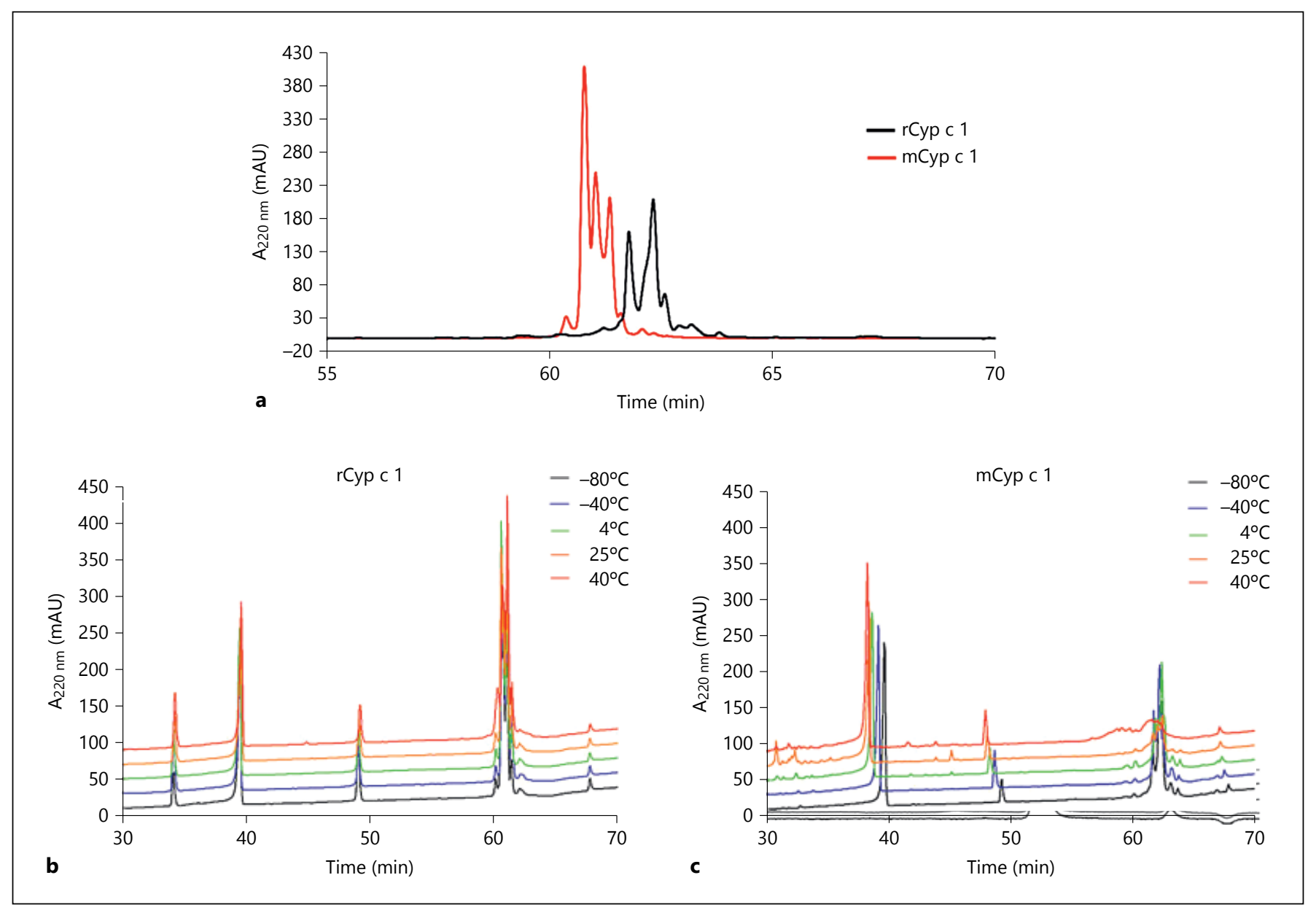

Fig. 4. RP-HPLC spectra of rCyp c 1 and mCyp c 1 at $t=0$ (a) and after stability studies $(t=6$ months; b, $\mathbf{c})$.

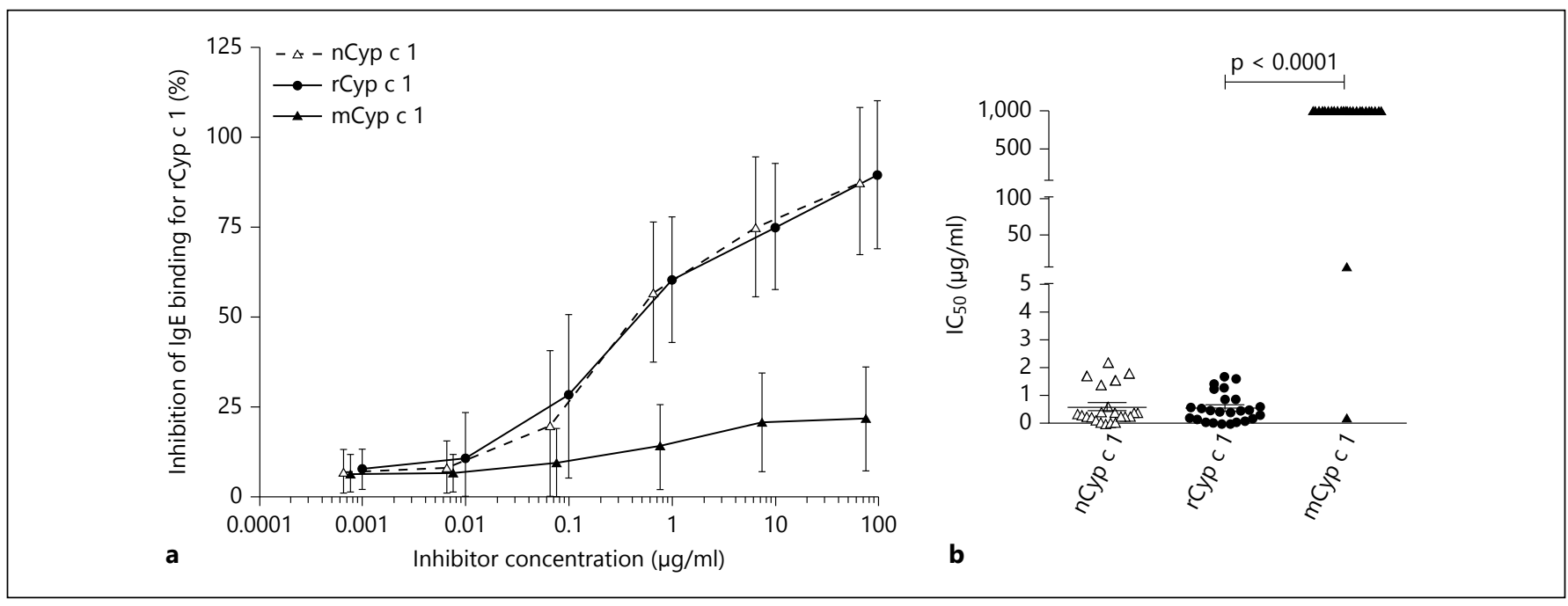

Fig. 5. ImmunoCAP inhibition experiments with $\mathrm{rCyp} \mathrm{c} 1$ on the ImmunoCAP and the natural and recombinant WT or mutant allergen as inhibitors. a Inhibition at different inhibitor concentrations. b Concentration of inhibitor needed for $50 \%$ inhibition $\left(\mathrm{IC}_{50}\right)$. 
Fig. 6. Mean histamine release obtained from stripped basophils sensitized with serum from fish-allergic donors $(n=13)$ with the natural and recombinant WT and mCyp c 1 molecule.

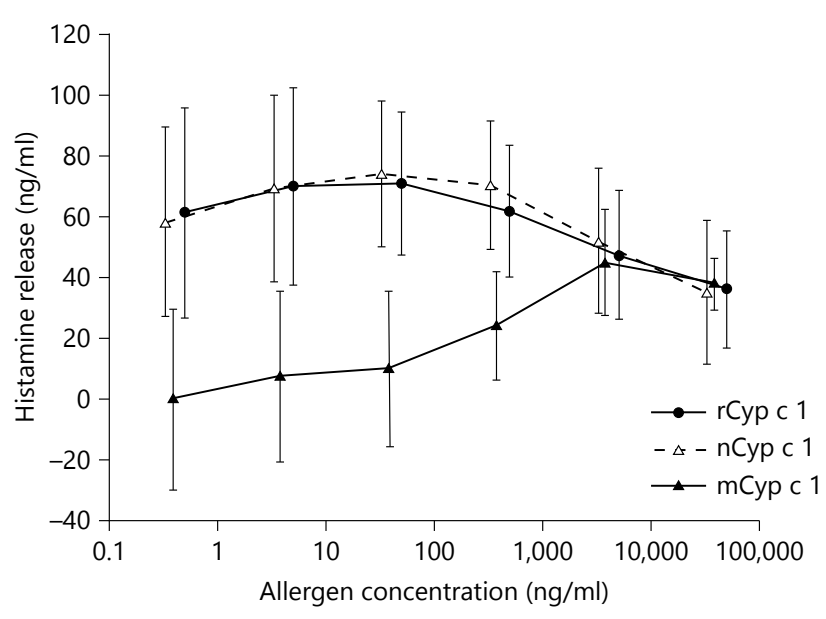

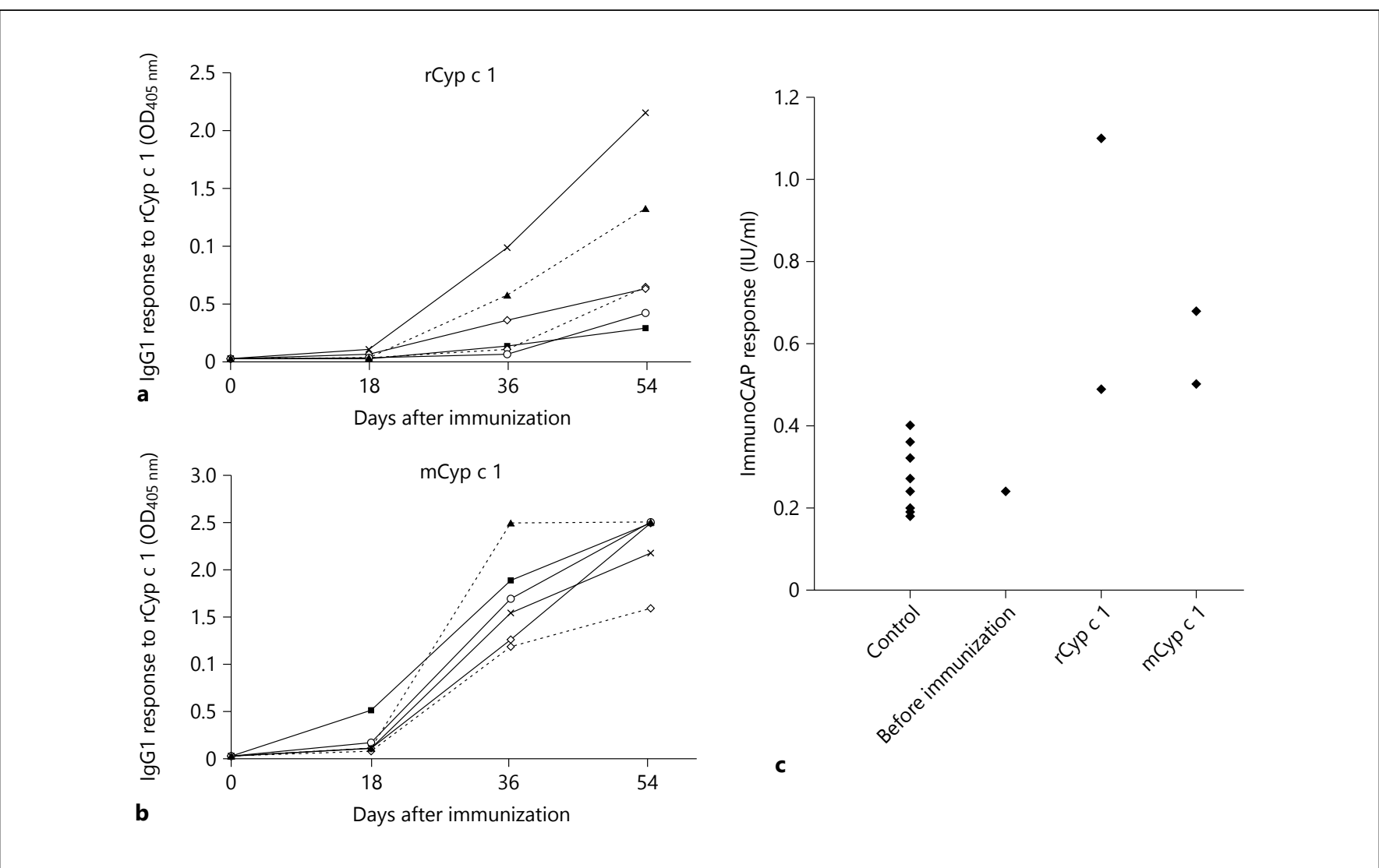

Fig. 7. a, b Development of rCyp c 1-specific IgG1 antibody responses obtained in BALB/c mice $(n=6)$ after subcutaneous immunization (10 $\mu$ g protein/mouse) with rCyp c 1 (a) and mCyp c 1 (b). Antibody levels were measured by ELISA and results are displayed as mean optical density (OD) values. c Development of
rCyp c 1-specific IgG antibody responses obtained in rabbits $(\mathrm{n}=$ 2) 60 days after subcutaneous immunization with rCyp c 1 and mCyp c 1 . Before immunization (pooled from $n=20$ ) and control values (anti-dog responses, $\mathrm{n}=8$ ) are shown. 
reason is that fish allergy is dominated by a single major allergen, parvalbumin. This is a clear advantage when developing a treatment based on recombinant allergen technology. Of course a parvalbumin-based treatment will cover most but not all fish-allergic patients, but preselecting on a sensitization to parvalbumin is easy with currently available reagents for component-resolved diagnosis [2].

Why did we choose the subcutaneous route? To the best of our knowledge, all current initiatives to develop immunotherapies for food allergies (e.g. to egg, milk and peanut) focus on the oral, sublingual or epicutaneous route [22-27]. SCIT has a long track record for efficient treatment of respiratory (pollen and house dust mite) and insect venom allergies [28-30], inducing long-lasting tolerance [31,32]. Although sublingual treatments of respiratory allergies have gained a substantial market share, patient compliance is generally regarded as poor compared to injections given by a specialist in a well-controlled setting [33]. Immunotherapy for food allergy is most relevant for those patients at risk of developing severe potentially life-threatening reactions. In particular for that group, well-controlled administration, where compliance can be monitored reliably by experienced specialists, is of utmost importance. This is underscored by the first oral and sublingual immunotherapy trials for food allergy, where in the majority of patients protection (desensitization) is lost within weeks after termination of the treatment [34-36]. With this in mind, poor compliance to a daily oral or sublingual administration may put patients with severe food allergies at risk of severe reactions when resuming the treatment or when accidentally exposed to the food.

On the other hand, the safety profile of subcutaneous treatment for food allergy piloted for peanut in the early 90 s of the previous century has been very poor. Aqueous peanut extract caused severe side effects requiring epinephrine and other rescue medication at high frequency [4]. Therefore, any strategy towards SCIT for food allergies should have a significantly improved safety profile. In the FAST project, we developed a hypoallergenic mutant of the major fish allergen parvalbumin, mCyp c 1 , and adsorbed this molecule to aluminum hydroxide to further decrease the risk of allergic side effects. Aluminum hydroxide is widely applied in SCIT for respiratory and venom allergies in Europe, but not in the USA. The safety issues observed with the use of aqueous peanut extract for SCIT warrant a discussion in the USA about the use of alum for increasing the safety of SCIT for the treatment of food allergies.

Development Hypoallergenic

Parvalbumin for SCIT
Based on earlier reports with (hypoallergenic) recombinant vaccines [37-40] and the current and earlier preclinical data obtained with mCyp c 1[41], it is to be expected that the current mCyp c 1-based vaccine will induce allergen-specific blocking of IgG antibodies that can inhibit mast cell and basophil triggering and IgE-facilitated antigen presentation [42]. By conserving T-cell epitopes, the vaccine is also suitable to induce anti-inflammatory Cyp c 1-specific regulatory $\mathrm{T}$ cells that will inhibit Cyp c 1-induced allergic inflammation [43].

Overall, one can hypothesize that immunotherapy with mCyp c 1 will dampen Th2/IgE-skewed allergic immune responses by induction of blocking $\mathrm{IgG} / \mathrm{IgG}_{4}$ antibodies and of $\mathrm{T}_{\text {reg }} / \mathrm{Th} 1$-type responses $[44,45]$. Two alternative strategies for increasing safety and efficacy of immunotherapy under development are aiming at reducing the risk of anaphylactic side effects by either just targeting the T-cell arm (T-cell epitope peptide immunotherapy) [46] or the induction of blocking IgG antibodies (B-cell epitope peptides conjugated to immunogenic carrier proteins) [44, and references therein]. In FAST, the strategy was to develop a drug substance that unites these two complimentary strategies into a single molecule: a hypoallergen with largely retained T-cell reactivity and the potency to induce blocking of IgG antibodies. In addition, the molecule needed to have physicochemical properties that guaranteed sufficient stability for a future pharmaceutical product and proven absence of toxic properties in laboratory animals. This paper reports the successful development of mCyp c 1 as a stable soluble molecule that is hypoallergenic and has retained its $\mathrm{T}$-cell reactivity and potency to induce IgG antibodies that cross-react with the native allergen. Although on average an impressive 1,000fold reduction in allergenic activity was reached, for some patients the reduction was significantly less, i.e. 10-fold and 100-fold, respectively. Therefore, a skin test reagent for mCyp c 1 was formulated that will be used to prescreen patients for their individual sensitivity to the hypoallergen. Although a positive skin prick test cannot be directly translated into possible side effects upon subcutaneous administration of alum-adsorbed mCyp $c 1$, it is an extra precaution that may help identifying patients that are more likely to develop potentially more severe side effects.

Toxicity studies necessary to get permission for firstin-man administration did not reveal any toxic effects. Acute toxicity showed that a single application of mCyp c 1 in mice at a dose level corresponding to 800 -fold the highest anticipated absolute human dose, by using BSA normalization of the animal dose according to FDA guidelines $[47,48]$ (or $>10,000$ times the maximum dose 
based on BW) was tolerated well. Repeated dose toxicity was assessed using three dosages at 33, 110 and 333 times the maximum dose (based on $\mathrm{BW}$ ) in the protocol for the planned clinical trial, i.e. $60 \mu \mathrm{g}$ mCyp c 1 adsorbed to $1 \mathrm{mg}$ of alum. All three dosages tested in mice were administered using the same absolute quantity of alum, similar to the clinical trial described below. We observed that in the lower-dose groups IgE levels were high, whereas IgG levels were low (Th2 skewing), and this was reversed in the high-dose groups (a more Th1-like response).

The first-in-man clinical trial is a two-center, randomized, double-blind, placebo-controlled, clinical trial involving 16 fish-allergic subjects. The design is a 3 -armed clinical trial (placebo and two dosage schemes differing in dose by a factor 10) with patients randomized to one of both treatment groups $(\mathrm{n}=8)$. Within each group, 6 subjects are randomized to receive active treatment and 2 subjects are randomized to receive placebo. The patients are treated subcutaneously (SCIT) with mCyp c 1 formulated in a suspension with alum. The aim is to establish a safe dose of mCyp c 1 and to study the pharmacodynamics of the hypoallergen administered to human subjects. Particularly IgE, IgG 4 , IgA, T cells, skin prick test and histamine release will be monitored.

In conclusion, the FAST project has delivered a drug product based on mCyp $\mathrm{c} 1$ that is considered suitable for a safety phase I/IIa clinical trial in fish-allergic patients, for which ethical and regulatory approval has been obtained.

\section{References}

1 Sharp MF, Lopata AL: Fish allergy: in review. Clin Rev Allergy Immunol 2014;46:258-271.

2 Lopata AL, Lehrer SB: New insights into seafood allergy. Curr Opin Allergy Clin Immunol 2009;9:270-277.

3 Narisety SD, Keet CA: Sublingual vs oral immunotherapy for food allergy: identifying the right approach. Drugs 2012;72:1977-1989.

4 Nelson HS, Lahr J, Rule R, Bock A, Leung D: Treatment of anaphylactic sensitivity to peanuts by immunotherapy with injections of aqueous peanut extract. J Allergy Clin Immunol 1997;99:744-751.

5 Oppenheimer JJ, Nelson HS, Bock SA, Christensen F, Leung DY: Treatment of peanut allergy with rush immunotherapy. J Allergy Clin Immunol 1992;90:256-262.

6 Valenta R: The future of antigen-specific immunotherapy of allergy. Nat Rev Immunol 2002;2:446-453.

7 Zuidmeer-Jongejan L, Fernandez-Rivas M, Poulsen LK, Neubauer A, Asturias J, Blom L, Boye J, Bindslev-Jensen C, Clausen M, Ferrara R, Garosi P, Huber H, Jensen BM, Koppelman S, Kowalski ML, Lewandowska-Polak A, Linhart B, Maillere B, Mari A, Martinez A, Mills CE, Nicoletti C, Opstelten DJ, Papadopoulos NG, Portoles A, Rigby N, Scala E, Schnoor HJ, Sigursdottir S, Stavroulakis G, Stolz F, Swoboda I, Valenta R, van den Hout R, Versteeg SA, Witten M, van Ree R: FAST: towards safe and effective subcutaneous immunotherapy of persistent life-threatening food allergies. Clin Transl Allergy 2012;2:5.

8 Swoboda I, Bugajska-Schretter A, Linhart B, Verdino P, Keller W, Schulmeister U, Sperr WR, Valent P, Peltre G, Quirce S, Douladiris N, Papadopoulos NG, Valenta R, Spitzauer S: A recombinant hypoallergenic parvalbumin mutant for immunotherapy of IgE-mediated fish allergy. J Immunol 2007;178:6290-6296.

9 Griesmeier U, Vazquez-Cortes S, Bublin M, Radauer C, Ma Y, Briza P, Fernandez-Rivas
M, Breiteneder H: Expression levels of parvalbumins determine allergenicity of fish species. Allergy 2010;65:191-198.

10 Van Do T, Elsayed S, Florvaag E, Hordvik I, Endresen C: Allergy to fish parvalbumins: studies on the cross-reactivity of allergens from 9 commonly consumed fish. J Allergy Clin Immunol 2005;116:1314-1320.

11 Elsayed S, Apold J: Immunochemical analysis of cod fish allergen M: locations of the immunoglobulin binding sites as demonstrated by the native and synthetic peptides. Allergy 1983;38:449-459.

12 Aas K, Jebsen JW: Studies of hypersensitivity to fish. Partial purification and crystallization of a major allergenic component of cod. Int Arch Allergy Appl Immunol 1967;32:1-20.

13 Berchtold MW: Structure and expression of genes encoding the three-domain Ca2+-binding proteins parvalbumin and oncomodulin. Biochim Biophys Acta 1989;1009:201-215.

14 Heizmann CW, Hunziker W: Intracellular calcium-binding proteins: more sites than insights. Trends Biochem Sci 1991;16:98-103.

15 Ikura M: Calcium binding and conformational response in EF-hand proteins. Trends Biochem Sci 1996;21:14-17.

16 Bugajska-Schretter A, Elfman L, Fuchs T, Kapiotis S, Rumpold H, Valenta R, Spitzauer S: Parvalbumin, a cross-reactive fish allergen, contains IgE-binding epitopes sensitive to periodate treatment and $\mathrm{Ca} 2+$ depletion. J Allergy Clin Immunol 1998;101:67-74.

17 Swoboda I, Bugajska-Schretter A, Verdino P, Keller W, Sperr WR, Valent P, Valenta R, Spitzauer S: Recombinant carp parvalbumin, the major cross-reactive fish allergen: a tool for diagnosis and therapy of fish allergy. J Immunol 2002;168:4576-4584.

18 Bugajska-Schretter A, Grote M, Vangelista L, Valent P, Sperr WR, Rumpold H, Pastore A, Reichelt R, Valenta R, Spitzauer S: Purification, biochemical, and immunological char- acterisation of a major food allergen: different immunoglobulin E recognition of the apoand calcium-bound forms of carp parvalbumin. Gut 2000;46:661-669.

19 Skov PS, Pelck I, Ebbesen F, Poulsen LK: Hypersensitivity to the diphtheria component in the $\mathrm{Di}$-Te-Pol vaccine. A type I allergic reaction demonstrated by basophil histamine release. Pediatr Allergy Immunol 1997;8:156-158.

20 Linhart B, Bigenzahn S, Hartl A, Lupinek C, Thalhamer J, Valenta R, Wekerle T: Costimulation blockade inhibits allergic sensitization but does not affect established allergy in a murine model of grass pollen allergy. J Immunol 2007;178:3924-3931.

21 Parish CR, Glidden MH, Quah BJ, Warren HS: Use of the intracellular fluorescent dye CFSE to monitor lymphocyte migration and proliferation. Curr Protoc Immunol 2009;chapt 4:unit4.9, DOI: 10.1002/ 0471142735.im0409s84.

22 Clark AT, Islam S, King Y, Deighton J, Anagnostou K, Ewan PW: Successful oral tolerance induction in severe peanut allergy. Allergy 2009;64:1218-1220.

23 Keet CA, Frischmeyer-Guerrerio PA, Thyagarajan A, Schroeder JT, Hamilton RG, Boden S, Steele P, Driggers S, Burks AW, Wood RA: The safety and efficacy of sublingual and oral immunotherapy for milk allergy. J Allergy Clin Immunol 2012;129:448.e5-455.e5.

24 Varshney P, Jones SM, Scurlock AM, Perry TT, Kemper A, Steele P, Hiegel A, Kamilaris J, Carlisle S, Yue X, Kulis M, Pons L, Vickery B, Burks AW: A randomized controlled study of peanut oral immunotherapy: clinical desensitization and modulation of the allergic response. J Allergy Clin Immunol 2011;127:654-660.

25 Anagnostou K, Clark A, King Y, Islam S, Deighton J, Ewan P: Efficacy and safety of high-dose peanut oral immunotherapy with factors predicting outcome. Clin Exp Allergy 2011;41:1273-1281. 
26 Burks AW, Jones SM, Wood RA, Fleischer DM, Sicherer SH, Lindblad RW, Stablein D, Henning AK, Vickery BP, Liu AH, Scurlock AM, Shreffler WG, Plaut M, Sampson HA: Oral immunotherapy for treatment of egg allergy in children. N Engl J Med 2012; 367:233-243.

27 Dupont C, Kalach N, Soulaines P, LegoueMorillon S, Piloquet H, Benhamou PH: Cow's milk epicutaneous immunotherapy in children: a pilot trial of safety, acceptability, and impact on allergic reactivity. J Allergy Clin Immunol 2010;125:1165-1167.

28 Nouri-Aria KT, Wachholz PA, Francis JN, Jacobson MR, Walker SM, Wilcock LK, Staple SQ, Aalberse RC, Till SJ, Durham SR: Grass pollen immunotherapy induces mucosal and peripheral IL-10 responses and blocking IgG activity. J Immunol 2004;172:3252-3259.

29 Plewako H, Wosinska K, Arvidsson M, Bjorkander J, Hakansson L, Rak S: Production of interleukin- 12 by monocytes and interferongamma by natural killer cells in allergic patients during rush immunotherapy. Ann Allergy Asthma Immunol 2006;97:464-468.

30 Senti G, Johansen P, Martinez GJ, Prinz Varicka BM, Kundig TM: Efficacy and safety of allergen-specific immunotherapy in rhinitis, rhinoconjunctivitis, and bee/wasp venom allergies. Int Rev Immunol 2005;24:519-531.

31 Boyle RJ, Elremeli M, Hockenhull J, Cherry MG, Bulsara MK, Daniels M, Oude Elberink JN: Venom immunotherapy for preventing allergic reactions to insect stings. Cochrane Database Syst Rev 2012;10:CD008838.

32 Durham SR, Walker SM, Varga EM, Jacobson MR, O'Brien F, Noble W, Till SJ, Hamid QA, Nouri-Aria KT: Long-term clinical efficacy of grass-pollen immunotherapy. N Engl J Med 1999;341:468-475.

33 Kiel MA, Roder E, Gerth Van Wijk R, Al MJ, Hop WC, Rutten-van Mölken MP: Real-life compliance and persistence among users of subcutaneous and sublingual allergen immunotherapy. J Allergy Clin Immunol 2013;132: 353-360.

34 Brozek JL, Terracciano L, Hsu J, Kreis J, Compalati E, Santesso N, Fiocchi A, Schunemann HJ: Oral immunotherapy for IgE-mediated cow's milk allergy: a systematic review and meta-analysis. Clin Exp Allergy 2012;42:363374.
35 Sheikh A, Nurmatov U, Venderbosch I, Bischoff E: Oral immunotherapy for the treatment of peanut allergy: systematic review of six case series studies. Prim Care Respir J 2012;21:41-49.

36 Fisher HR, Du Toit G, Lack G: Specific oral tolerance induction in food allergic children: is oral desensitisation more effective than allergen avoidance?: a meta-analysis of published RCTs. Arch Dis Child 2011;96:259264.

37 Jutel M, Jaeger L, Suck R, Meyer H, Fiebig H, Cromwell O: Allergen-specific immunotherapy with recombinant grass pollen allergens. J Allergy Clin Immunol 2005;116:608-613.

38 Niederberger V, Horak F, Vrtala S, Spitzauer S, Krauth MT, Valent P, Reisinger J, Pelzmann M, Hayek B, Kronqvist M, Gafvelin G, Gronlund $\mathrm{H}$, Purohit A, Suck R, Fiebig $\mathrm{H}$, Cromwell O, Pauli G, van Hage-Hamsten M, Valenta R: Vaccination with genetically engineered allergens prevents progression of allergic disease. Proc Natl Acad Sci U S A 2004 101(suppl 2):14677-14682.

39 Pauli G, Larsen TH, Rak S, Horak F, Pastorello E, Valenta R, Purohit A, Arvidsson M, Kavina A, Schroeder JW, Mothes N, Spitzauer S, Montagut A, Galvain S, Melac M, Andre C, Poulsen LK, Malling HJ: Efficacy of recombinant birch pollen vaccine for the treatment of birch-allergic rhinoconjunctivitis. J Allergy Clin Immunol 2008;122:951-960.

40 Reisinger J, Horak F, Pauli G, van Hage M, Cromwell O, König F, Valenta R, Niederberger V: Allergen-specific nasal IgG antibodies induced by vaccination with genetically modified allergens are associated with reduced nasal allergen sensitivity. J Allergy Clin Immunol 2005; 116:347-354.

41 van der Ventel ML, Nieuwenhuizen NE, Kirstein F, Hikuam C, Jeebhay MF, Swoboda I, Brombacher F, Lopata AL: Differential responses to natural and recombinant allergens in a murine model of fish allergy. Mol Immunol 2011;48:637-646.
42 Pree I, Shamji MH, Kimber I, Valenta R, Durham SR, Niederberger V: Inhibition of CD23dependent facilitated allergen binding to $\mathrm{B}$ cells following vaccination with genetically modified hypoallergenic Bet v 1 molecules. Clin Exp Allergy 2010;40:1346-1352.

43 Gafvelin G, Thunberg S, Kronqvist M, Gronlund $\mathrm{H}$, Gronneberg R, Troye-Blomberg $\mathrm{M}$, Akdis M, Fiebig H, Purohit A, Horak F, Reisinger J, Niederberger V, Akdis CA, Cromwell O, Pauli G, Valenta R, van Hage M: Cytokine and antibody responses in birch-pollen-allergic patients treated with genetically modified derivatives of the major birch pollen allergen Bet $\mathrm{v} 1$. Int Arch Allergy Immunol 2005;138:59-66.

44 Burks AW, Calderon MA, Casale T, Cox L, Demoly P, Jutel M, Nelson H, Akdis CA: Update on allergy immunotherapy: American Academy of Allergy, Asthma \& Immunology/ European Academy of Allergy and Clinical Immunology/PRACTALL consensus report. J Allergy Clin Immunol 2013;131:1288-1296.

45 Focke-Tejkl M, Valenta R: Safety of engineered allergen-specific immunotherapy vaccines. Curr Opin Allergy Clin Immunol 2012; 12:555-563.

46 Mackenzie KJ, Fitch PM, Leech MD, Ilchmann A, Wilson C, McFarlane AJ, Howie SE, Anderton SM, Schwarze J: Combination peptide immunotherapy based on T-cell epitope mapping reduces allergen-specific $\operatorname{IgE}$ and eosinophilia in allergic airway inflammation. Immunology 2013;138:258268.

47 Guidance for Industry, Estimating the Maximum Safe, Starting Dose in Initial Clinical Trials for Therapeutics in Adult Healthy Volunteers. US Department of Health and $\mathrm{Hu}$ man Services, Food and Drug Administration, Center for Drug Evaluation and Research (CDER), 2005, pp 1-30, http://www. fda.gov/downloads/Drugs/Guidances/ UCM078932.pdf.

48 Center for Drug Evaluation and Research, Center for Biologics Evaluation and Research: Estimating the Safe Starting Dose in Clinical Trials for Therapeutics in Adult Healthy Volunteers. Rockville, US Food \& Drug Administration, 2002
Development Hypoallergenic

Parvalbumin for SCIT
Int Arch Allergy Immunol 2015;166:41-51 DOI: $10.1159 / 000371657$ 